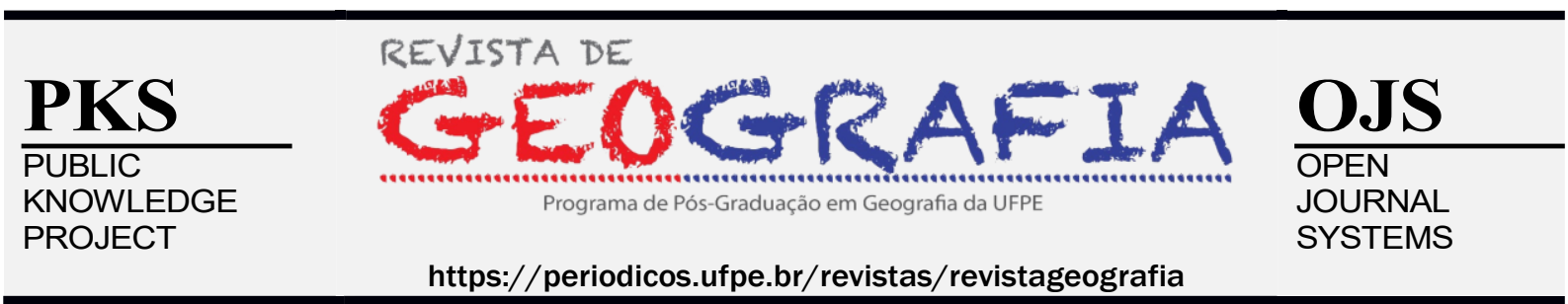

\title{
ANÁLISE CLIMÁTICA DO ALTO VALE DA BACIA HIDROGRÁFICA DO RIO PIRACURUCA, DIVISA ENTRE OS ESTADOS DO CEARÁ E DO PIAUÍ
}

\author{
Francílio de Amorim dos Santos ${ }^{1}$, Maria Lúcia Brito da Cruz $^{2}$
}

${ }^{1}$ Instituto Federal de Educação, Ciência e Tecnologia do Piauí - IFPI. E-mail: francilio.amorim@ifpi.edu.br. ORCID: http://orcid.org/0000-0002-0415-6673.

${ }^{2}$ Universidade Estadual do Ceará - UECE. E-mail: mlbcruz@gmail.com. ORCID: http://orcid.org/0000-00022202-923X.

Artigo recebido em 13/04/2020 e aceito em 11/03/2021

\begin{abstract}
RESUMO
O objetivo da pesquisa foi realizar análise dos aspectos climáticos do Alto Vale da bacia hidrográfica do rio Piracuruca, situado entre os estados do Ceará e do Piauí, por meio do emprego de técnicas de geoprocessamento. Para o estudo foram obtidos dados de precipitação de dez postos pluviométricos, do Sistema de Informações Hidrológicas (HidroWeb), junto da Agência Nacional de Águas (ANA), de 1985 a 2016. Os dados foram refinados no pacote de programas USUAIS e espacializados no QGIS, via método peso pelo inverso da distância (IDW). Dessa forma, o Alto Vale da bacia do rio Piracuruca exibiu o predomínio das seguintes características: precipitação com 1.227 a $1.387 \mathrm{~mm}$; temperaturas que variam de 22,2 a $24,2^{\circ} \mathrm{C}$; perca de água por evapotranspiração da ordem 1.102 a $1.302 \mathrm{~mm}$; três a quatro meses secos; excedente hídrico de 433 a $733 \mathrm{~mm}$; déficit hídrico de 106 a 306 mm; aridez média a alta; severidade climática média. Os resultados apresentados reafirma-se a influência exercida pelo planalto da Ibiapaba no condicionamento climático da área.
\end{abstract}

Palavras-chave: Bacia Hidrográfica; Aspectos Climáticos; Geoprocessamento.

\section{GEOPROCESSING APPLIED TO CLIMATE ANALYSIS OF THE HIGH VALLEY OF THE PIRACURUCA RIVER WATER BASIN, A BORDER BETWEEN THE STATES OF CEARÁ AND OF PIAUÍ}

\begin{abstract}
The objective of this research was to analyze the climatic aspects of the Upper Valley of the Piracuruca River Basin, located between the states of Ceará and Piauí, using geoprocessing techniques. The descriptive study required obtaining rainfall data from ten rainfall stations, from the Hydrological Information System (HidroWeb), of the National Water Agency (NWA), considering the historical series from 1985 to 2016. These data were refined using the USUAIS software package and spatialized in the QGIS, via the inverse distance weight (IDW) method. Thus, the Upper Valley of the Piracuruca River Basin exhibited the predominance of the following characteristics: precipitation whit 1227 to 1387 $\mathrm{mm}$; temperatures ranging from 22.2 to $24.2^{\circ} \mathrm{C}$; water loss by evapotranspiration of the order 1102 to $1302 \mathrm{~mm}$; three to four dry months; water surplus of 433 to $733 \mathrm{~mm}$; water deficit of 106 to $306 \mathrm{~mm}$;
\end{abstract}


medium to high aridity; average climate severity. The results presented reaffirm the influence exerted by the Ibiapaba plateau on the climatic conditioning of the area.

Keywords: Hydrographic Sub-basin; Climatic Aspects; Geoprocessing.

\section{INTRODUÇÃO}

Dentre os principais aspectos que compreende a paisagem do Nordeste do Brasil, os aspectos climáticos possivelmente sejam os mais marcantes, particularmente por ter influência direta sobre a modelação do relevo, na formação dos solos e na composição florística. Ressaltase, ainda, a interferência climática no uso das terras e, como tal, no desenvolvimento das atividades humanas ao longo do tempo.

Desse modo, torna-se relevante a realização de estudos ligados ao conhecimento das condicionantes climáticas, frente sua relevância e influência em diversos campos naturais e humanos. Reitera-se, também, a importância de estudos sobre a referida temática como ponto de partida para planejamento das atividades humanas ou base para estudos posteriores, ligados a desastres naturais, resiliência climática, entre outros.

Nesse cenário, é essencial citar a importância do uso de técnicas de geoprocessamento para localização, espacialização e compreensão dos fenômenos, notadamente dos aspectos climáticos do Alto Vale da bacia hidrográfica do rio Piracuruca, situado entre os estados do Ceará e do Piauí. O trecho em questão compreende uma área de 2.904,4 km², abrangendo território de sete municípios cearenses e cinco municípios piauienses.

Ressalta-se que o estudo considerou apenas a análise do Alto Vale devido sua dinâmica diferenciada em relação às demais áreas da bacia em questão, pois se destaca por apresentar um maior nível de umidade e, como tal, menor rigor climático. Dessa forma, foi empreendido um estudo classificado como descritivo quanto ao seu objetivo demandou aquisição de dados alfanuméricos de dez postos pluviométricos da Agência Nacional de Águas (ANA, 2017), considerando série histórica de 1985 a 2016, devido à disponibilidade de dados para a área estudada.

Reitera-se que esses dados foram utilizados na possibilidade de apresentar dados mais próximos da realidade local. Dessa forma, essas informações foram manuseadas e refinadas através do pacote de programas USUAIS e, posteriormente, espacializadas por meio das 
ferramentas de geoprocessamento do Sistema de Informação Geográfica (SIG) QGIS, versão 2.14 - Essen.

Nesse contexto, considerou-se pertinente e relevante o desenvolvimento da pesquisa, que teve como objetivo realizar análise dos aspectos climáticos do Alto Vale da bacia hidrográfica do rio Piracuruca, situado entre os estados do Ceará e do Piauí, por meio do emprego de técnicas de geoprocessamento.

\section{PROCEDIMENTOS METODOLÓGICOS}

A área em estudo

A pesquisa tomou como recorte espacial o Alto Vale da bacia hidrográfica do rio Piracuruca (AVSBHP), área compreende $2.904,4 \mathrm{~km}^{2}$ e sete municípios cearenses - Carnaubal, Guaraciaba do Norte, Ibiapina, São Benedito, Tianguá, Ubajara e Viçosa do Ceará - e cinco municípios piauienses - Cocal, Cocal dos Alves, Domingos Mourão, Piracuruca e São João da Fronteira -, conforme Figura 1.

Figura 1 - Localização do Alto Vale da bacia hidrográfica do rio Piracuruca, situado entre os estados do Ceará e do Piauí.

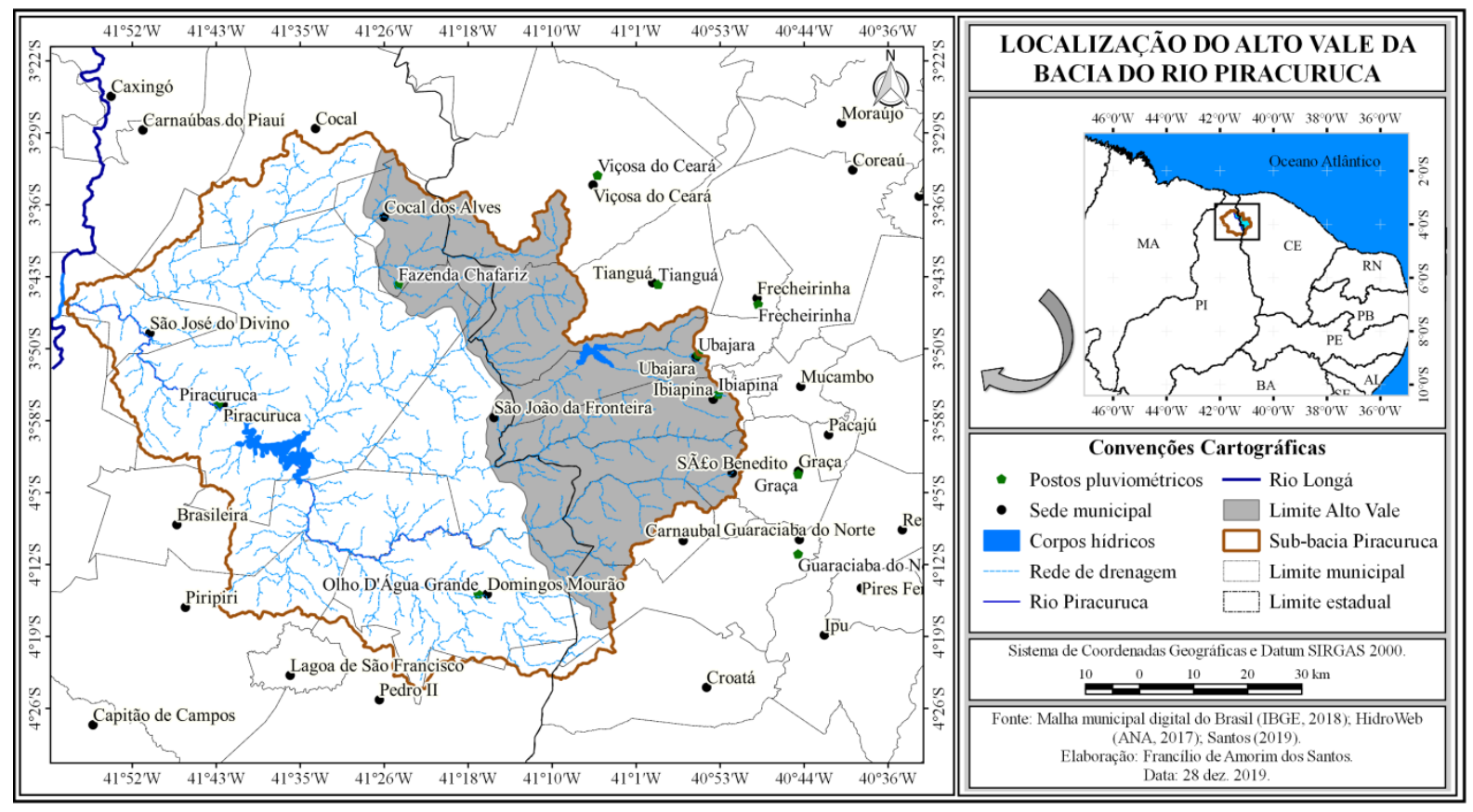

Fonte: Elaborado pelos autores (2019). 
Ressalta-se que dos municípios, mencionados, cinco deles apresentam suas sedes inseridas nos limites do Alto Vale, sendo eles: Ibiapina, São Benedito, Ubajara, Cocal dos Alves e São João da Fronteira. O AVSBHP assenta-se sobre o Planalto da Ibiapaba, onde se situam as principais nascentes do rio Piracuruca, a área destaca-se, ainda, pela presença do açude Jaburu II, recurso hídrico de grande relevância para o abastecimento humano e desenvolvimento de atividades agropecuárias, principalmente a fruticultura (SANTOS, 2019).

\section{Procedimentos técnico-operacionais}

O estudo constou da análise das seguintes componentes climáticas: precipitação, temperatura, evapotranspiração potencial, número de meses secos, excedente hídrico e déficit hídrico. Ressalta-se, também, a execução da análise do índice efetivo de umidade, índice de aridez e índice de severidade climática.

Para atingir o objetivo proposto foi necessária aquisição de dados de precipitação de dez postos pluviométricos (Figura 1), junto ao Sistema de Informações Hidrológicas (HidroWEB), da Agência Nacional de Águas (ANA, 2017), a partir da série histórica de 1985 a 2016. De posse desses dados, efetuaram-se várias rotinas no pacote de programas USUAIS (Figura 2), para refinamento dos dados dos postos pluviométricos, conforme sugerem Oliveira e Sales (2016). Destaca-se que os elementos analisados foram espacializados no SIG QGIS, versão 2.14 - Essen, por meio do método peso pelo inverso da distância (IDW).

Figura 2 - Rotinas executadas no pacote de programas USUAIS, para refinamento dos dados de pluviométricos.

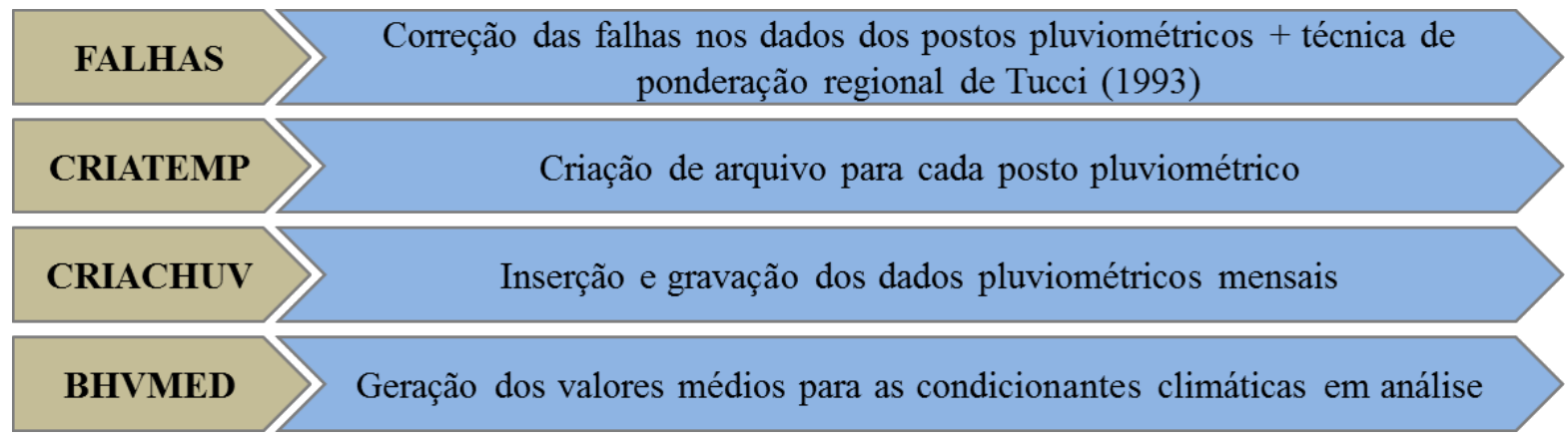

Fonte: Oliveira e Sales (2016). Adaptado pelos autores (2019). 
Salienta-se que a Evapotranspiração potencial (Etp) foi calculada considerando o valor de $125 \mathrm{~mm}$ como capacidade de armazenamento de água no solo, conforme sugere a proposta de Thornthwaite (1948). Por sua vez, os valores de temperatura média mensal foram calculados por meio de equações, seguindo a metodologia de Lima, Alencar e Coelho (1982).

O Índice efetivo de umidade ( $\mathrm{Im}$ ), que representa uma forma de mensurar o nível de umidade do clima de determinada área, baseou-se na combinação dos valores de evapotranspiração potencial, do excedente hídrico e do déficit hídrico (THORNTHWAITE; MATHER, 1955), conforme está representado na Equação 1. Ressalta-se que partir dessa metodologia foram geradas três classes para o índice efetivo de umidade, a saber: superúmido (> 100), úmido (20 a 100) e subúmido úmido (0 a 20).

$$
I m=\frac{[(E x c-D e f) * 100]}{E t p}
$$

Onde: $\mathrm{Im}=$ é o índice efetivo de umidade; Exc = é o excedente hídrico anual; Def = é o déficit hídrico anual; Etp = é a evapotranspiração potencial anual.

O Índice de aridez (Ia), inicialmente desenvolvido por Thornthwaite (1941) e aperfeiçoado por Penman (1953), foi produzido considerando-se o quociente entre a precipitação média anual e a evapotranspiração potencial anual, conforme pode ser observado na Equação 2. Destaca-se que as classes delimitadas para o ia foram adaptadas a partir das faixas sugeridas pela United Nations Environment Programme (UNEP, 1991), quais sejam: muito baixa (1,64 a 1,90); baixa $(1,38$ a 1,64), média $(1,12$ a 1,38), alta $(0,86$ a 1,12$)$ e muito alta $(0,60$ a 0,86$)$.

$$
I a=\left(\frac{P}{E t p}\right)
$$

Onde: $\mathrm{Ia}=$ é o índice de aridez; $\mathrm{P}=$ é a precipitação média anual; Etp = é a evapotranspiração potencial anual.

O índice de severidade climática (Isc) foi obtido por meio de álgebra de mapas, cujo procedimento foi executado no QGIS. Esse índice, de acordo com Santos (2015), é construído a partir do produto entre o índice efetivo de umidade e o número de meses secos. Para o referido 
índice delimitaram-se as seguintes classes: baixa (3 a 6), média (6 a 10) e alta severidade climática (10 a 12). Ressalta-se que os intervalos para as três classes foram definidos por meio do estilo graduado e método de quebras naturais (jenks), posto de acordo com os testes realizados foi o método que mais se adequou à área estudada.

\section{RESULTADOS E DISCUSSÃO}

O Alto Vale da bacia do rio Piracuruca encontra-se sob a influência da Zona de Convergência Intertropical (ZCIT), que é representada por uma ou mais faixas de nuvens e que constituem o principal sistema atmosférico provedor de chuvas no setor norte do Nordeste do Brasil. Esse sistema atua, particularmente, entre os meses de março e abril, quando atinge sua posição mais meridional.

Ressalta-se que o posicionamento da ZCIT sofre interferência dos fenômenos oceânicos El niño Oscilação Sul (ENOS) e a diferença da temperatura da superfície das bacias do Atlântico Norte e Atlântico Sul, o dipolo. Essa interferência resulta em anos normais e anômalos, com precipitações abaixo da média histórica, em geral provocando secas/estiagens, ou acima da média, geralmente resultando em enchentes/inundações (XAVIER, 2001; FERREIRA; MELLO, 2005).

A Figura 3 apresenta os valores médios anuais espacializados da precipitação, temperatura e evapotranspiração potencial do Alto Vale da bacia do rio Piracuruca, para o período de 1985 a 2016. Observa-se que o topo do planalto da Ibiapaba, particularmente onde se situam as sedes dos municípios de Ibiapina e Ubajara exibem os maiores volumes pluviométricos, as menores temperaturas e evapotranspiração potencial.

Por outro lado, em direção ao território piauiense esses valores invertem-se, ou seja, com o distanciamento do topo do planalto os níveis de precipitação vão reduzindo, já as temperaturas e a perca de água por evapotranspiração tende a aumentar. Pois o fator orográfico oriundo do planalto da Ibiapaba condiciona maior concentração de umidade, que gera condições climáticas adequadas para o desenvolvimento de horti e fruticultura, com destaque para os municípios de Tianguá e Ubajara (SANTOS; NASCIMENTO, 2015).

Por sua vez, a Figura 4 expõe em valores percentuais as classes de precipitação, de temperatura e de evapotranspiração potencial do Alto Vale da bacia do rio Piracuruca, para o período de 1985 a 2016. Na área observa-se, desse modo, o predomínio das seguintes classes: 
intervalos de precipitação com 1.227 a $1.307 \mathrm{~mm}$ e 1.307 a $1.387 \mathrm{~mm}$, que juntas somam 62,1\% $\left(1.803,7 \mathrm{~km}^{2}\right)$ do volume total que ocorre na área estudada; temperaturas de 22,2 a $23,2{ }^{\circ} \mathrm{C}$ e 23,2 a $24,2^{\circ} \mathrm{C}$, que ocorrem em $61,7 \%\left(1.792,0 \mathrm{~km}^{2}\right)$ da área total do Alto Vale; classe de evapotranspiração situada entre 1.102 a 1.202 e 1.202 a 1.302, que representam 62,3\% (1.809,5 $\mathrm{km}^{2}$ ) do volume de água perdida em toda a área pesquisada.

Figura 3 - Dados médios anuais espacializados para a precipitação, temperatura e evapotranspiração potencial do Alto Vale da bacia do rio Piracuruca, para o período de 1985 a 2016.
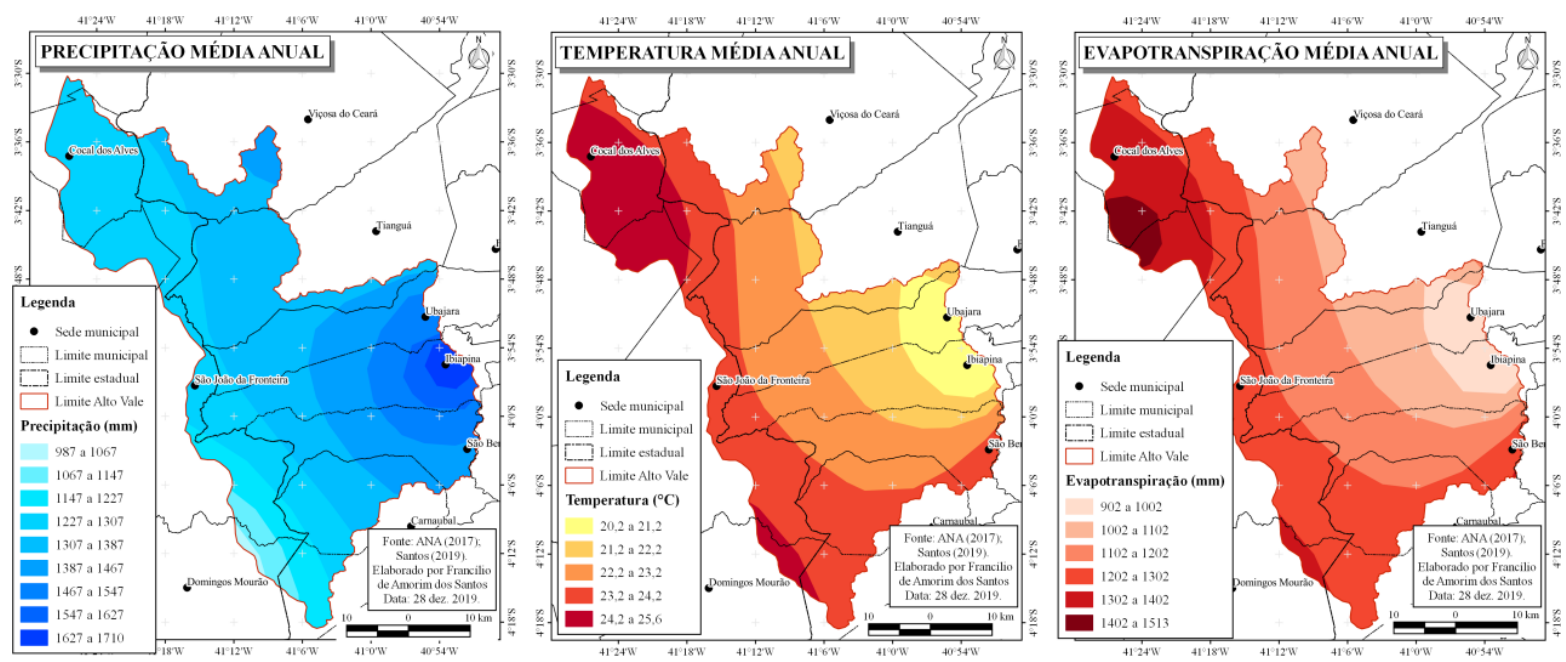

Fonte: Elaborado pelos autores (2019). 
Figura 4 - Percentual das classes de precipitação, de temperatura e da evapotranspiração potencial do Alto Vale da bacia do rio Piracuruca, média anual para o período de 1985 a 2016.

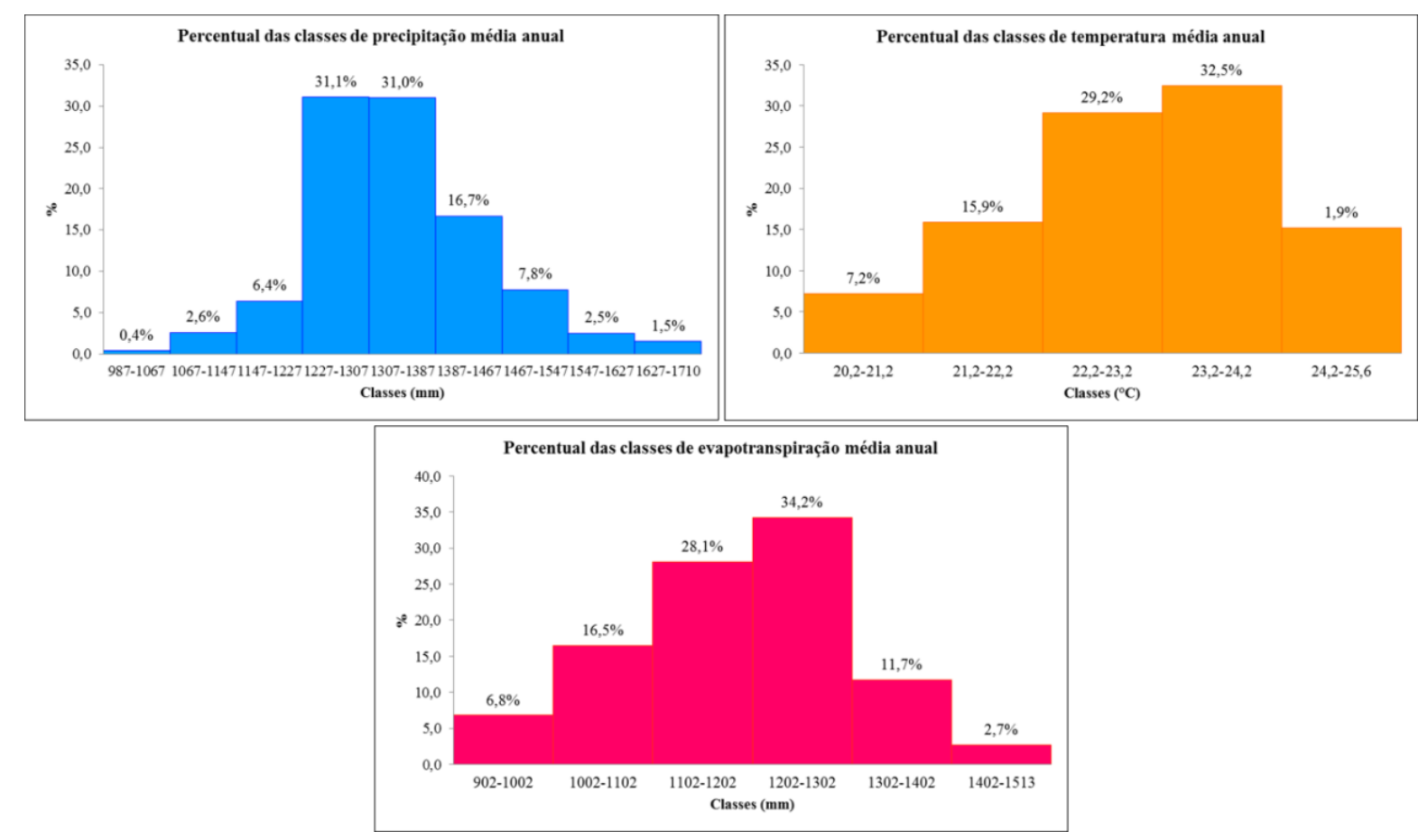

Fonte: Elaborado pelos autores (2019).

Na Figura 5 podem-se observar os valores espacializados para o número de meses secos, excedente hídrico e déficit hídrico do Alto Vale da bacia do rio Piracuruca, considerando o período de 1985 a 2016. Logo, visualiza-se que o número de meses secos cresce do topo do planalto para o território piauiense, podendo chegar a 5 meses secos, fato que pode ser explicado pelo maior condicionamento de umidade no topo do planalto. $\mathrm{O}$ excedente e o déficit hídrico seguem o mesmo sentido, onde se tem o topo com o mais elevado volume de excedente e o menor déficit hídrico, com destaque para o local onde se situam as sedes dos municípios de Ibiapina e Ubajara. 
Figura 5 - Dados médios anuais espacializados para o número de meses secos, excedente hídrico e déficit hídrico do Alto Vale da bacia do rio Piracuruca, para o período de 1985 a 2016.
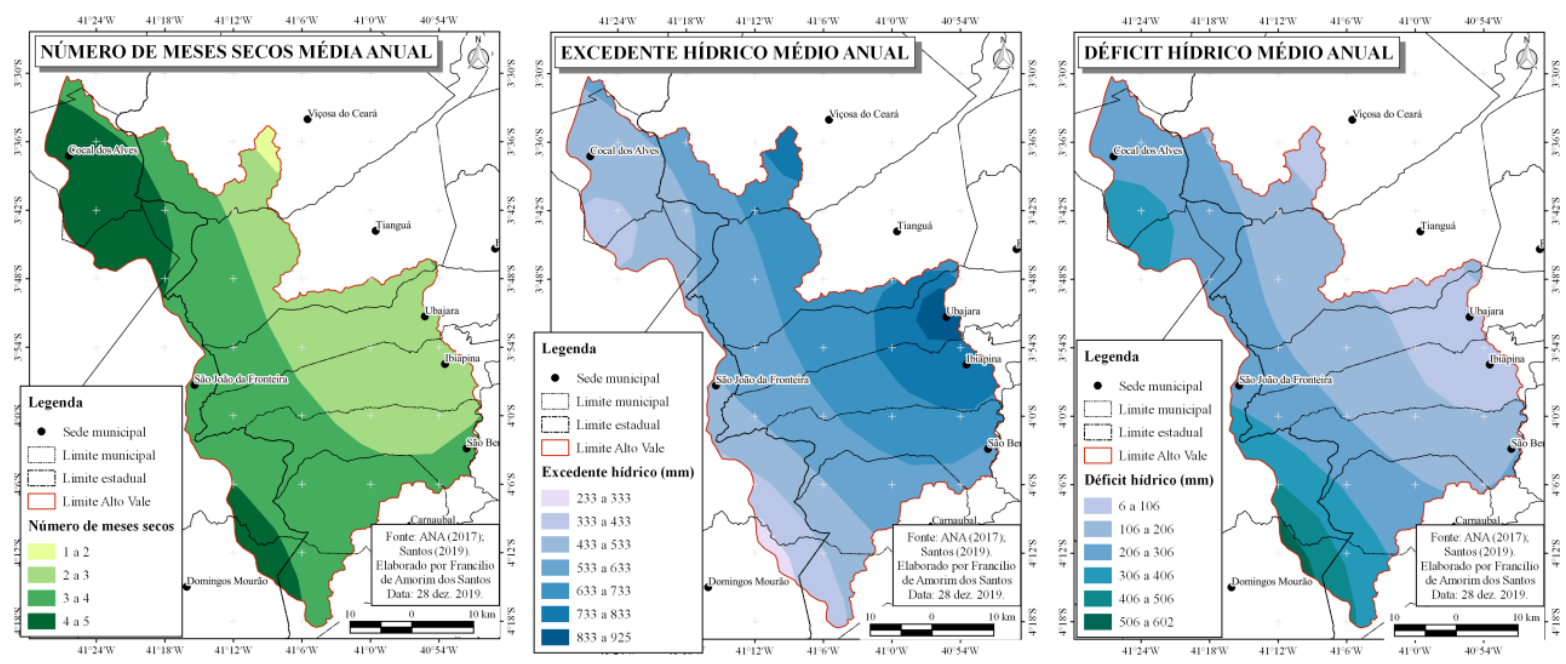

Fonte: Elaborado pelos autores (2019).

Na Figura 6 visualizam-se os valores percentuais para as classes do número de meses secos, excedente hídrico e déficit hídrico do Alto Vale da bacia do rio Piracuruca, a partir do período de 1985 a 2016. Dessa forma, pode ser observado o predomínio de três a quatro meses secos em 48,3\% (1.202,8 $\left.\mathrm{km}^{2}\right)$ da área estudada. Ao passo que o excedente hídrico do Alto Vale atinge um volume de 433 a $733 \mathrm{~mm}$, ocorrendo em 79,0\% (2.294,4 km²) de sua área. Por sua vez, o déficit hídrico predominante no Alto Vale varia de 106 a $306 \mathrm{~mm}$, distribuindo-se por $68,7 \%\left(1.995,3 \mathrm{~km}^{2}\right)$ de sua área. 
Figura 6 - Percentual das classes do número de meses secos, excedente hídrico e déficit hídrico do Alto Vale da bacia do rio Piracuruca, média anual para o período de 1985 a 2016.

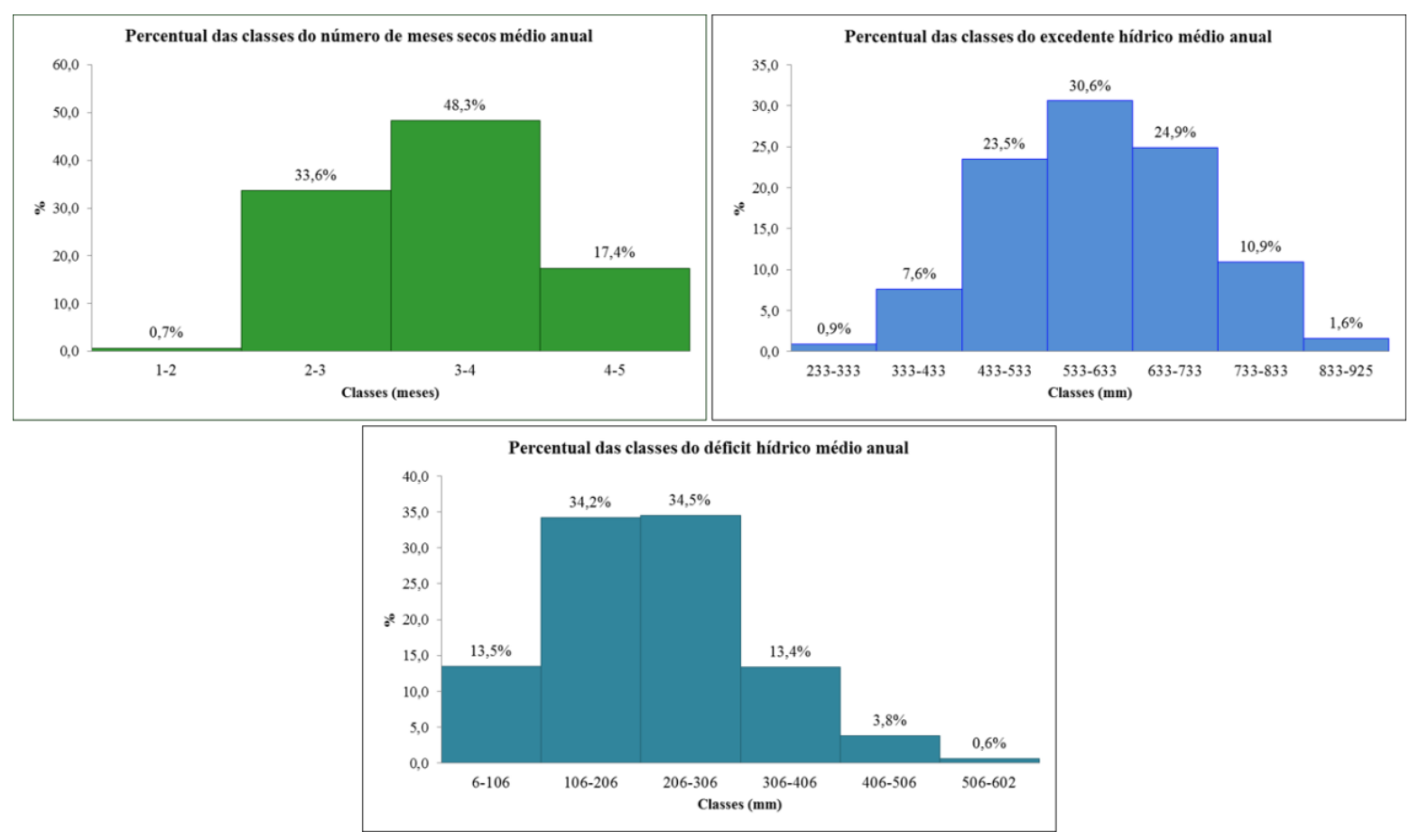

Fonte: Elaborado pelos autores (2019).

A Figura 7 compreende a espacialização dos dados médios anuais para o índice efetivo de umidade, índice de aridez e índice de severidade climática do Alto Vale da bacia do rio Piracuruca, a partir do período de 1985 a 2016. Desse modo, pode-se observar que na área estudada ocorre grande concentração de umidade, com existência de três tipos climáticos, a saber: superúmido, úmido e subúmido úmido.

O índice de aridez indicou cinco classes de aridez (Figura 7), cujo aumento é diretamente proporcional ao afastamento do topo do planalto. Por seu turno, o índice de severidade climática reafirma a influência do planalto da Ibiapaba no condicionamento da umidade e do rigor climático no trecho estudado, posto que o topo apresente condições mais amenas, em detrimento de seus rebordos que exibem maior rigor climático, notadamente em direção ao estado do Piauí. Logo, o menor rigor climático nessa área possibilita o desenvolvimento de atividades econômicas diferenciadas em relação ao restante da bacia, que apresenta maior rigor climático. 
Figura 7 - Dados médios anuais espacializados para o índice efetivo de umidade, índice de aridez e índice de severidade climática do Alto Vale da bacia do rio Piracuruca, para o período de 1985 a 2016.
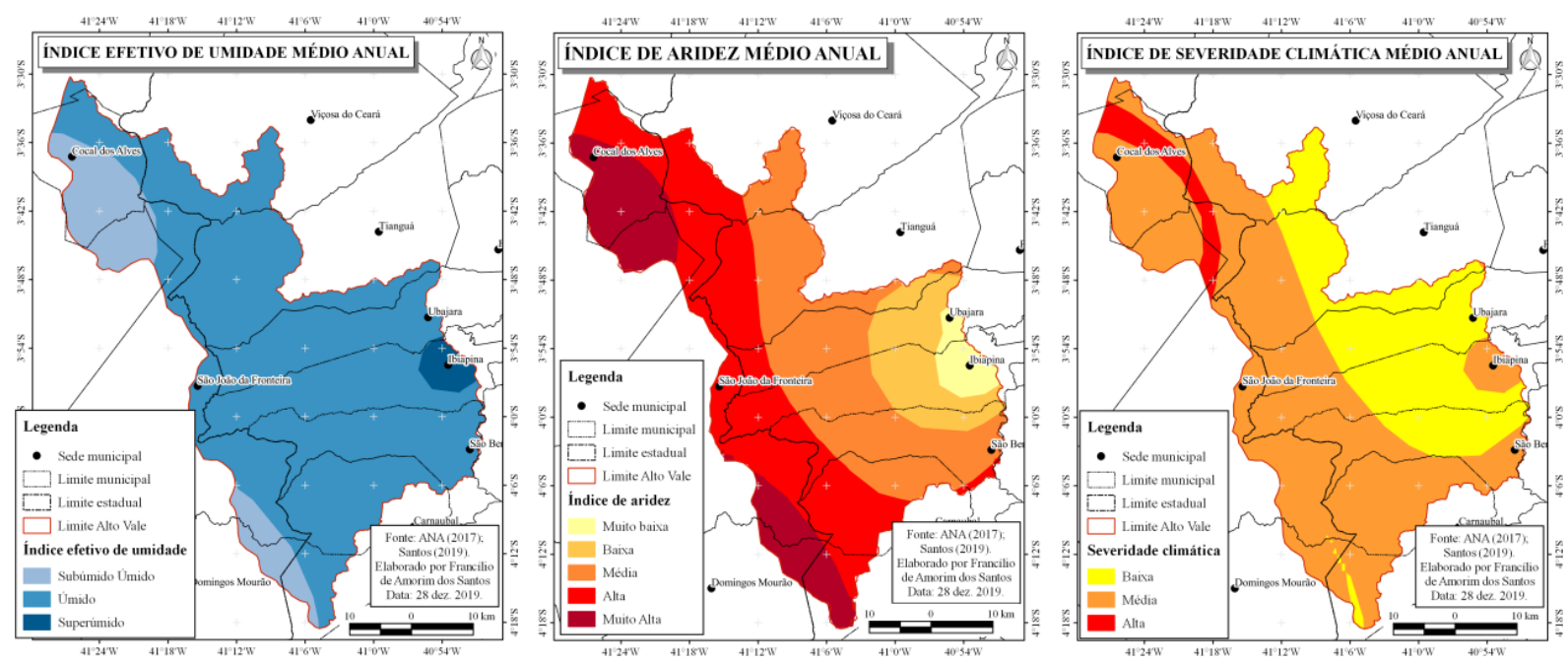

Fonte: Elaborado pelos autores (2019).

Na Figura 8 apresentam os valores percentuais das classes do índice efetivo de umidade, índice de aridez e índice de severidade climática do Alto Vale da bacia do rio Piracuruca, para o período de 1985 a 2016. Nesse sentido, visualiza-se a predominância da tipologia climática úmida por $84,4 \%\left(2.451,3 \mathrm{~km}^{2}\right)$ da área do Alto Vale. No que diz respeito aos níveis de aridez observa-se a preponderância das classes média e alta, que juntas somam $69,4 \%\left(2.015,7 \mathrm{~km}^{2}\right)$. Por sua vez, a classe de severidade climática de maior ocorrência na área estudada diz respeito à classe média, que se distribui por $62,8 \%\left(1.824,0 \mathrm{~km}^{2}\right)$.

Diante do exposto, acima, evidencia-se a influência do planalto da Ibiapaba sobre as condições climáticas do Alto Vale da bacia hidrográfica do rio Piracuruca, resultando em menor rigor climático se comparado aos demais setores da bacia, ou seja, apresenta elevados níveis de precipitação, temperatura mais amenas, aridez e severidade climática reduzida, entre outros. Esse fato possibilidade desenvolvimento de atividades diferenciadas, posto que o nível de umidade seja maior, logo, é possível otimizar o uso a partir das potencialidades, particularmente àquelas vinculadas aos elementos climáticos analisados nesse estudo. 
Figura 8 - Percentual das classes do índice efetivo de umidade, índice de aridez e índice de severidade climática do Alto Vale da bacia do rio Piracuruca, média anual para o período de 1985 a 2016.

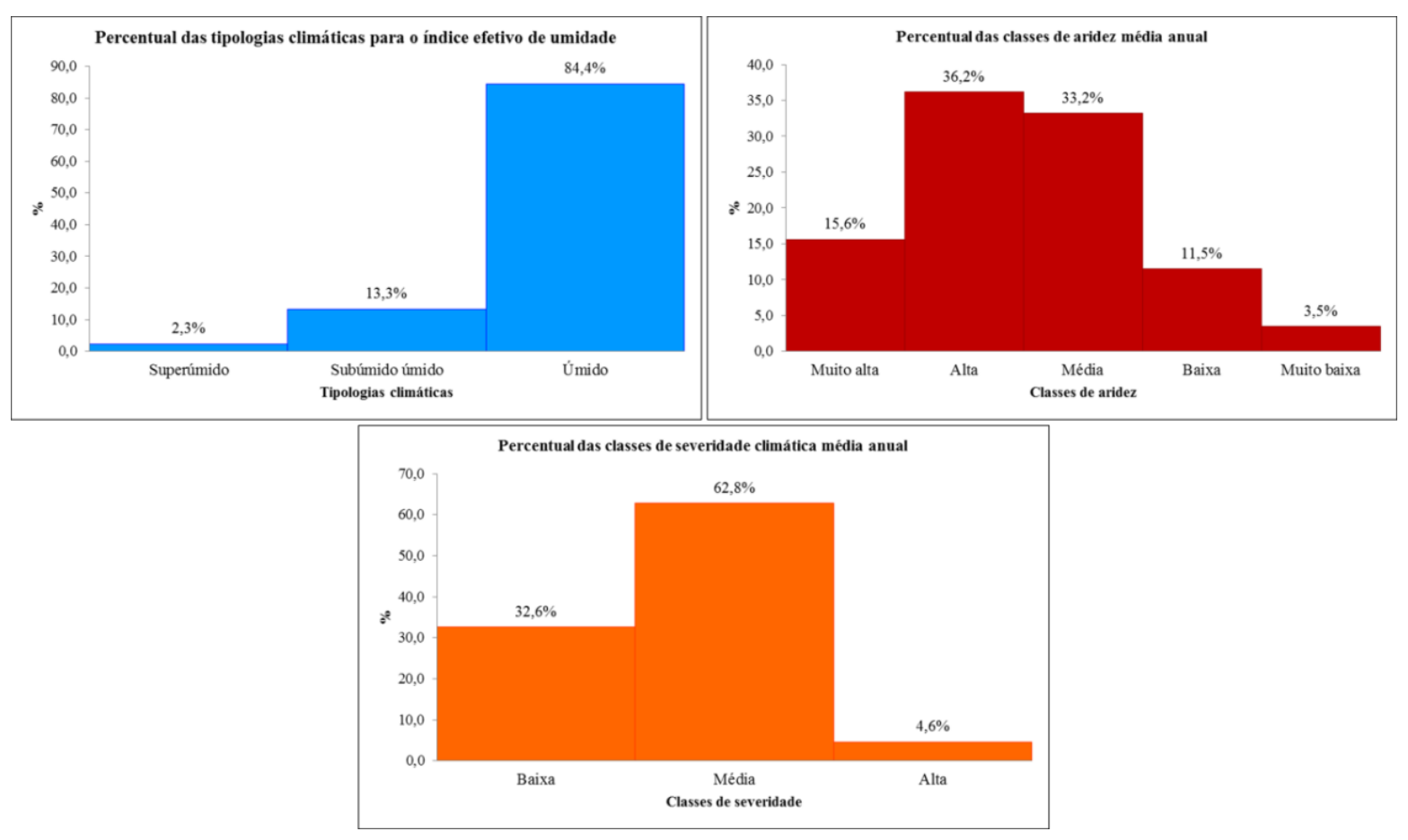

Fonte: Elaborado pelos autores (2019).

\section{CONSIDERAÇÕES FINAIS}

Frente ao que foi exposto, reafirma-se a influência exercida pelo planalto da Ibiapaba no condicionamento climático da área. Infere-se, ainda, que o trecho estudado apresenta condições climáticas diversificadas, cujo topo exibe menor rigor climático, ou seja, maior volume pluviométrico, menores temperaturas médias, menor perca de água por evapotranspiração, maior excedente hídrico e menor déficit hídrico. Cita-se a ocorrência da tipologia climática superúmida e úmida, menor nível de aridez e menor severidade climática.

Por outro lado, nos rebordos do planalto em direção ao estado do Piauí ocorrem as áreas de maior rigor climático do Alto Vale, notadamente, por apresentar menores volumes de precipitação, as mais altas temperaturas médias, maiores volumes de água perdida via evapotranspiração, menor excedente hídrico, maior déficit hídrico, clima com tipologia subúmida, maior nível de aridez e a mais acentuada severidade climática.

Dessa forma, enfatiza-se a relevância da metodologia empregada pela pesquisa, posto que se tenha possibilitado realizar análise dos principais aspectos climáticos do Alto Vale da 
bacia hidrográfica do rio Piracuruca. Em suma, o estudo configura ponto de partida para planejamento das atividades humanas na área e base de informações para pesquisas posteriores, a exemplos de estudos específicos sobre secas ou inundações, tipologias de desastres naturais que periodicamente atingem o recorte espacial pesquisado.

\section{REFERÊNCIAS}

AGÊNCIA NACIONAL DE ÁGUAS. HidroWeb - Sistema de Informações Hidrológicas. Séries históricas: ano de 1985 a 2016. Disponível em <http://hidroweb.ana.gov.br/>. Acesso em: 11 fev. 2017.

FERREIRA, A.G.; MELLO, N.G.S. Principais sistemas atmosféricos atuantes sobre a região Nordeste do Brasil e a influência dos Oceanos Pacífico e Atlântico no clima da região. Revista Brasileira de Climatologia, Curitiba, v.1, n.1, p.15-28, dez. 2005.

INSTITUTO BRASILEIRO DE GEOGRAFIA E ESTATÍSTICA. Malha municipal digital do Brasil: situação em 2018. Rio de Janeiro: IBGE, 2018. Disponível em: $<$ http://downloads.ibge.gov.br/downloads_geociencias.htm>. Acesso em: 10 jun. 2019.

LIMA, M.G.; ALENCAR, P.A.M.; COELHO, H. Normais de temperatura máxima, mínima e média estimadas em função da latitude, longitude e altitude para o estado do Piauí. Ensaios: Boletim de Pesquisa, v.1, n.1, p.1-40, 1982.

OLIVEIRA, J.G.B.; SALES, M.C.L. Usuais: programas para uso em análise ambiental. Revista Equador (UFPI), Teresina, v.5, n.2, p.36-60, Janeiro/Junho, 2016.

PENMAN, H.L. The Physical Bases of Irrigation Control, in Report 13th Int. Hort. Congr., 2, 11 pages, Royal Horticultural Society, London, 1953.

SANTOS, F.A. Mapeamento das unidades geoambientais e estudo do risco de degradação/desertificação nos municípios de Castelo do Piauí e Juazeiro do Piauí. 187p. Dissertação (Mestrado em Geografia) - Universidade Federal do Piauí. Teresina, 2015.

SANTOS, F.A. Resiliência ambiental a secas e a inundações na Sub-bacia Hidrográfica do rio Piracuruca (CE-PI). 268p. Tese (Doutorado em Geografia) - Universidade Estadual do Ceará. Fortaleza, 2019.

SANTO, F. L. A; Nascimento, F. R. Zoneamento ecológico-econômico do planalto da Ibiapaba nos municípios de Tianguá e Ubajara - Noroeste do Ceará. Revista GeoUECE, Fortaleza, v.4, n.6, p.233. 2015.

THORNTHWAITE, C.W. An approach toward a rational Classification of Climate. The Geographical Review. New York, v.38, p.55-94, 1948. 
. Atlas of Climatic Types in the United States. Miscell Publ., n.421, U.S. Departament of Agricultures, Forest Service, 1941.

THORNTHWAITE, C.W; MATHER, J.R. The Water Balance: publications in climatology. New Jersey: Centerton, v.8, n.1, 1955.

TUCCI, C.E.M. Hidrologia: ciência e aplicação. Porto Alegre: Eds. da UFRGS e da USP, 1993.

UNITED NATIONS ENVIRONMENT PROGRAMME. Status of desertification and implementation of the United Nations Plan of Action to Combat Desertification. Nairóbi, 1991.

XAVIER, T.M.B.S. "Tempo de Chuva": estudos climáticos e de previsão para o Ceará e Nordeste setentrional. Fortaleza: ABC Editora, 2001. 478p. 